\title{
Public Awareness,
}

\section{Knowledge of Availability,}

And Willingness to Use

Neurosurgical Care Services

in Africa: A Cross-Sectional

E-Survey Protocol

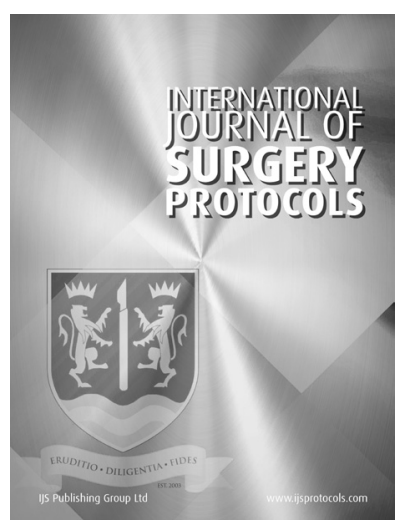

\section{CHIBUIKEM IKWUEGBUENYI [D \\ GIDEON ADEGBOYEGA (D)}

DANIEL SAFARI NTERANYA (D)

ARSENE DANIEL NYALUNDJA (D)

MICHAEL A. BAMIMORE (D)

*Author affiliations can be found in the back matter of this article

\section{LORRAINE ARABANG SEBOPELO (D)}

ULRICK SIDNEY KANMOUNYE (D)
PROTOCOL

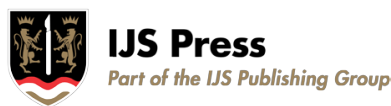

\section{ABSTRACT}

Background: Barriers to care cause delays in seeking, reaching, and getting care. These delays affect low-and middle-income countries (LMICs), where 9 out of 10 LMIC inhabitants have no access to basic surgical care. Knowledge of healthcare utilization behavior within underserved communities is useful when developing and implementing health policies. Little is known about the neurosurgical health-seeking behavior of African adults. This study evaluates public awareness, knowledge of availability, and readiness for neurosurgical care services amongst African adults.

Methodology: The cross-sectional study will be run using a self-administered e-survey hosted on Google Forms (Google, CA, USA) disseminated from 10th May 2021 to 10th June 2021. The Questionnaire would be in two languages, English and French. The survey will contain closed-ended, open-ended, and Likert Scale questions. The structured questionnaire will have four sections with 42 questions; Sociodemographic characteristics, Definition of neurosurgery care, Knowledge of neurosurgical diseases, practice and availability, and Common beliefs about neurosurgical care. All consenting adult Africans will be eligible. A minimum sample size of 424 will be used. Data will be analyzed using SPSS version 26 (IBM, WA, USA). Odds ratios and their 95\% confidence intervals, Chi-Square test, and ANOVA will be used to test for associations between independent and dependent variables. A P-value $<0.05$ will be considered statistically significant. Also, a multinomial regression model will be used.

Dissemination: The study findings will be published in an academic peer-reviewed journal, and the abstract will be presented at an international conference.

\section{Highlights}

- The burden of neurosurgical diseases is enormous in low- and middle-income countries, especially in Africa.

- Unfortunately, most neurosurgical needs in Africa are unmet because of delays in seeking, reaching, and getting care.

- Most efforts aimed at reducing barriers to care have focused on improving the neurosurgical workforce density and infrastructure. Little or no efforts have been directed towards understanding or reducing the barriers to seeking care.

CORRESPONDING AUTHOR:

\section{Chibuikem Ikwuegbuenyi}

Research Department, Association of Future African Neurosurgeons, Immeuble Nziko, Rue Marie Gocker, Mfoundi, Yaounde, Centre, Cameroon

Ikwuegbuenyichibuikem@ gmail.com

KEYWORDS:

Africa; Health seeking behavior; Global neurosurgery

TO CITE THIS ARTICLE: Ikwuegbuenyi C, Adegboyega G, Nyalundja AD, Bamimore MA, Nteranya DS, Sebopelo LA, Kanmounye US. Public Awareness, Knowledge of Availability, And Willingness to Use Neurosurgical Care Services in Africa: A CrossSectional E-Survey Protocol. International Journal of Surgery: Protocols. 2021; 25(1), pp. 123-128. DOI: https://doi. org/10.29337/ijsp.149 
- We aimed to understand public awareness, willingness to use, and knowledge of the availability of neurosurgical care in Africa.

- The study findings can inform effective strategies that promote the utilization of neurosurgical services and patient education in Africa.

\section{INTRODUCTION}

More than two-thirds of the global population lacks access to appropriate surgical care. An estimated 140 million necessary surgical procedures are left undone, resulting in excessive economic costs and profound disability and death [1]. There is a gross discrepancy in the availability of health resources for surgery, leaving a huge treatment gap geographically; this gap is seen particularly in Africa and Southeast Asia [2]. A huge disproportion exists in health care access in low- and middle-income countries (LMICS), where 9 out of 10 people have no access to basic surgical care [3]. There exist multiple factors that increase the delay to surgical care [4, 5]. A widely used framework in many areas of global health, including surgery, is the three-delay framework - seeking, reaching, and receiving health care $[6,7]$.

A review by Grimes et al. mentioned that barriers that limit access to surgery in LMICs are cultural (acceptability) and structural (accessibility), and to a significant extent, financial (affordability) [8]. Other studies identified low levels of health literacy and outdated medical facilities as barriers to surgical care [8-15]. Most of the efforts to reduce the barriers to neurosurgical care have been focused on improving the workforce density and the infrastructure via the provision of standard neurosurgical education and training and the provision of neurosurgical infrastructure $[16,17]$. While this is important, patients who need the services will only use them if they are willing to and are aware that these services exist in their community.

Healthcare-seeking behavior (HSB) is "any action or inaction which is undertaken by individuals who perceive themselves to have a health problem or to be ill to find an appropriate remedy" [18]. HSB can be appropriate or inappropriate. Appropriate HSB refers to "consulting a qualified medical professional or seeking healthcare at orthodox health facilities such as private clinics, primary health centers, and general hospitals during illness episodes or any situation requiring medical attention" [18]. Inappropriate HSB has been linked to worse health outcomes, increased morbidity and mortality, and poorer health statistics [19, 20]. In Nigeria, rural dwellers are more likely to exhibit inappropriate HSB than urban dwellers [21]. Other determinants of HSB include geographical proximity, socio-economic class, culture, political affiliation, education level, and the healthcare systems themselves $[22,23]$. Most rural dwellers use health facilities outside their villages because they lack access to these services in their local areas [24].
Africans attribute metaphysical characteristics, such as witchcraft/sorcery, to neurological diseases, including epilepsy, and this, in turn, causes stigmatization of people with epilepsy, thereby affecting the HSB [24]. In Ethiopia, patients report that their religion plays a critical role in their attitude towards neurosurgical procedures [25]. Similarly, Nigerian patients turn to religion for comfort after learning about their neurosurgical disease [26]. In Kenya, almost $70 \%$ of pregnant women within households in the upper socio-economic stratum deliver in health facilities compared with $42 \%$ among pregnant women in the middle socio-economic stratum and 38\% in the low socio-economic stratum [27].

The lack of knowledge and general misperceptions regarding neurosurgical care are considerable barriers to neurosurgical care, and further education of the general public would be of great value. To develop effective strategies to promote the utilization of neurosurgical services in Africa, we must explore demographic characteristics and barriers related to general public awareness of neurosurgical services and intentions for use and knowledge of availability. Knowledge of healthcare utilization behavior within communities is useful when developing health policies and implementing health programs [28]. We, therefore, aim with this paper to understand the public awareness of neurosurgical care, willingness to use, and knowledge of the availability.

\subsection{AIMS AND OBJECTIVES}

Aims: To map out public awareness, knowledge of availability, and readiness for neurosurgical care services amongst adult Africans.

\section{METHODS AND ANALYSIS \\ 2.1. STUDY DESIGN}

This cross-sectional study will use a self-administered e-survey to collect public awareness, knowledge of availability, and readiness for neurosurgical care services in Africa. A team of African neurosurgeons and patients will be consulted to assess the questionnaire's face validity. This team will check the questionnaire for duplication, confusing terms, and leading questions. We will use the team's feedback to improve the survey. Next, the questionnaire will be piloted among an arbitrary sample size of 20 respondents to identify technical issues with the survey. We will use Cronbach's alpha to evaluate the questionnaire's internal consistency and principal component analysis to identify factor loadings. Next, we will make revisions accordingly. 


\subsection{ELIGIBILITY CRITERIA}

- Inclusion Criteria: All consenting adult Africans who are not studying towards a healthcare degree or working in the healthcare sector.

- Exclusion Criteria: All medical/dental/nursing/allied health students and workers. This group will be excluded because it is expected that members will have better knowledge and more positive attitudes towards neurosurgical care than the general public.

\subsection{DATA COLLECTION TOOLS AND TECHNIQUE}

Self-administered structured Google Form (Google, CA, USA) questionnaires in French and English will be used for the study. The survey will contain closed-ended, open-ended, and Likert Scale questions. The structured questionnaire will have four sections (A-D). They are:

Section A - Sociodemographic characteristics (7): Age, gender, marital status, Nationality, Occupation, Urban/Rural settlement, Length of living in the region.

Section B - Definition of neurosurgery care (2): Respondents will be asked to define neurosurgery in their own words, then asked to select from several options disorders that can be treated with Neurosurgical care.

Section C - Knowledge of neurosurgical diseases, practice, and availability (11).

Section D - Common beliefs about neurosurgical care (12).

Written consent will be obtained from the respondents before the administration of questionnaires.

\subsection{SAMPLE SIZE}

The sample size was determined using the Normal approximation to the hypergeometric: $\mathrm{n}=\mathrm{n}=\mathrm{Nz} \wedge 2 \mathrm{pq} /$ $\left(E^{\wedge} 2(N-1)+z^{\wedge} 2 p q\right)[29]$

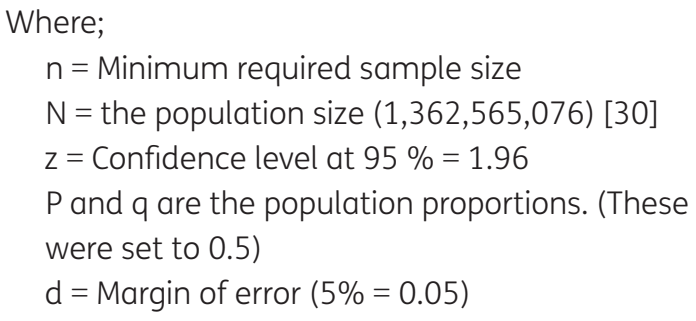

Employing a standard normal deviate of $1.96 \%$ at $95 \%$ confidence level and a maximal allowable difference from a true population of $5 \%(0.05)$, the sample size will be:

$$
\begin{aligned}
\mathrm{n} & =N z^{\wedge} 2 p q /\left(E^{\wedge} 2(N-1)+z^{\wedge} 2 p q\right) \\
& =385
\end{aligned}
$$

The sample size was then increased by $10 \%$ to allow for contingencies such as non-response.

$$
\begin{aligned}
n+10 \% \text { of } n & =385+[(10 / 100) * 385] \\
& =385+(0.1 * 385) \\
& =382+38.5 \\
& =423.5 \\
& =424
\end{aligned}
$$

Therefore, the sample size (n) is equal to 424 .

\subsection{OUTCOME MEASURES}

The primary outcome is the level of knowledge about the availability of the services.

Secondary outcomes will include the level of knowledge and beliefs about neurosurgical disease and the knowledge level of neurosurgical practice in Africa.

\subsection{DATA ANALYSIS}

Independent variables will include age, sex, marital status, profession, nationality, urban/rural residency, previous experience with neurosurgery. Dependent variables will include the level of knowledge and willingness to use neurosurgical services.

Data will be analyzed using SPSS version 26 (IBM, WA, USA). The analyzed univariable data will be presented as frequency tables and charts. The levels of knowledge will be stratified into five groups equally spaced: deficient, sufficient, satisfactory, good, and very good. The Q-Q plot will be used to evaluate the distribution of quantitative data. Also, the odds ratios and their 95\% confidence intervals, Chi-Square or Fisher's Exact Test, and ANOVA or Kruskal-Wallis test will be used to quantify associations between independent and dependent variables. Next, the independent variables will be integrated into a multinomial regression model.

\subsection{ETHICS}

Approval to carry out this study was obtained from the institutional review board of Bel Campus University of Technology, Kinshasa, DRC (No 2135488). The participants will be informed of the reason and nature of the study. Informed consent will be sought, and the participants will be informed of their right to withdraw at any point of the study. Participants will not be coerced to participate in the study, and confidentiality will be maintained throughout the study.

\section{LIMITATIONS}

Internet access remains low in many African countries, making this study inaccessible to a wide audience, especially those who seek or have used neurosurgical facilities in remote areas. Therefore, this provides 
an opportunity for researchers to conduct a large population-based survey in the future to get an idea of the ampleness of public awareness, knowledge of availability, and availability of neurosurgical care services in Africa by including both the population in remote areas and those who do not speak English or French.

Socioeconomic status and the education level of citizens are some of the factors that will limit the generalizability of our results. Citizens in the higher income bracket and those with a higher level of education are perhaps more likely to have more access to the internet and a better understanding of research goals.

\section{CONCLUSION}

Although there has been an increase in access to neurosurgical care in Africa, the unmet need remains significant. One reason this might be the case is that African neurosurgical patients experience multiple barriers to seeking care. Therefore, we must understand the role of HSBs in bridging the treatment gap. This study will survey the public awareness of neurosurgical care services intended for use, knowledge of availability, and readiness for neurosurgical care services in Africa.

\section{DISSEMINATION}

We plan to publish this review in a peer-reviewed journal. We may also present this review at local and/or international conferences.

\section{ABBREVIATIONS}

LMICs, Low-and middle-income countries; HSB, Healthcare seeking behavior; MT, Medical tourism.

\section{ADDITIONAL FILES}

The additional file for this article can be found as follows:

- Appendix 1. Questionnaires in French and English, Adapted from [31]. DOI: https://doi.org/10.29337/ijsp.149.s1

\section{FUNDING INFORMATION}

There was no funding for the current study protocol.

\section{COMPETING INTERESTS}

The authors declare that they have no known competing financial interests or personal relationships that could have appeared to influence the work reported in this paper.

\section{AUTHOR CONTRIBUTIONS}

Conceptualization: Chibuikem A. Ikwuegbuenyi, Ulrick Sidney Kanmounye

Methodology: Chibuikem A. Ikwuegbuenyi, Gideon Adegboyega, Michael A. Bamimore, Arsene Daniel Nyalundja, Daniel Safari Nteranya, Ulrick Sidney Kanmounye

Supervision: Ulrick Sidney Kanmounye

Writing-Original Draft: Chibuikem A. Ikwuegbuenyi, Gideon Adegboyega, Lorraine Arabang Sebopelo, Michael A. Bamimore, Arsene Daniel Nyalundja, Daniel Safari Nteranya

Writing-Reviewing \& Editing: Chibuikem A. Ikwuegbuenyi, Gideon Adegboyega, Lorraine Arabang Sebopelo, Ulrick Sidney Kanmounye.

\section{AUTHOR AFFILIATIONS}

Chibuikem Ikwuegbuenyi (D) orcid.org/0000-0003-3646-7713 Research Department, Association of Future African Neurosurgeons, Yaounde, Cameroon

Gideon Adegboyega (D) orcid.org/0000-0002-8912-4338 Research Department, Association of Future African Neurosurgeons, Yaounde, Cameroon; Queen Mary University of London, Barts and The London School of Medicine London, United Kingdom

Arsene Daniel Nyalundja (D) orcid.org/0000-0002-4802-3928 Research Department, Association of Future African Neurosurgeons, Yaounde, Cameroon; Department of Surgery, Hôpital Provincial General de Reference de Bukavu, Bukavu, Democratic Republic of Congo; Faculty of Medicine, Université Catholique de Bukavu, Bukavu, Democratic Republic of Congo

Michael A. Bamimore (D) orcid.org/0000-0003-2235-0282 Research Department, Association of Future African Neurosurgeons, Yaounde, Cameroon; School of Medicine, Philadelphia College of Osteopathic Medicine, Philadelphia, PA, United States

Daniel Safari Nteranya (D) orcid.org/0000-0001-5170-7442 Research Department, Association of Future African Neurosurgeons, Yaounde, Cameroon; Department of Surgery, University Clinics of Bukavu, Official University of Bukavu, Bukavu, Democratic Republic of Congo

Lorraine Arabang Sebopelo (D) orcid.org/0000-0003-3905-4834 Research Department, Association of Future African Neurosurgeons, Yaounde, Cameroon; Faculty of Medicine, University of Botswana, Gaborone, Botswana

Ulrick Sidney Kanmounye (D) orcid.org/0000-0001-6791-1018 Research Department, Association of Future African Neurosurgeons, Yaounde, Cameroon

\section{REFERENCES}

1. Shrime MG, Bickler SW, Alkire BC, Mock, C. Global burden of surgical disease: an estimation from the provider 
perspective. Lancet Glob. Health. 2015; 3S8-S9. DOI: https:// doi.org/10.1016/S2214-109X(14)70384-5

2. M P, S M, S S, Yc H, S P, A R, M D, Wd J, Kb P. Neurosurgical Care: Availability and Access in Low-Income and MiddleIncome Countries. World Neurosurg. 2018; 112. DOI: https:// doi.org/10.1016/j.wneu.2018.01.029

3. Meara JG, Greenberg SLM. Global surgery as an equal partner in health: no longer the neglected stepchild. Lancet Glob. Health. 2015; 3 S1-S2. DOI: https://doi.org/10.1016/ S2214-109X(15)70019-7

4. The Global Initiative for Children's Surgery, Concepcion TL, Dahir S, Mohamed M, Hiltbrunn K, Ismail EA, Poenaru D, Rice HE, Smith ER. Barriers to Surgical Care Among Children in Somaliland: An Application of the Three Delays Framework. World J. Surg. 2020; 44: 1712-1718. DOI: https://doi.org/10.1007/s00268-020-05414-4

5. Ologunde R, Maruthappu M, Shanmugarajah K, Shalhoub J. Surgical care in low and middle-income countries: Burden and barriers. Int. J. Surg. 2014; 12: 858-863. DOI: https:// doi.org/10.1016/j.ijsu.2014.07.009

6. Kakembo N, Godier-Furnemont A, Nabirye A, Cheung M, Kisa P, Muzira A, Sekabira J, Ozgediz D. Barriers to Pediatric Surgical Care in Low-Income Countries: The Three Delays' Impact in Uganda. J. Surg. Res. 2019; 242: 193-199. DOI: https://doi.org/10.1016/j.jss.2019.03.058

7. Thaddeus S, Maine D. Too far to walk: Maternal mortality in context. Soc. Sci. Med. 1994; 38: 1091-1110. DOI: https:// doi.org/10.1016/0277-9536(94)90226-7

8. Grimes CE, Bowman KG, Dodgion CM, Lavy CBD. Systematic Review of Barriers to Surgical Care in LowIncome and Middle-Income Countries. World J. Surg. 2011; 35: 941-950. DOI: https://doi.org/10.1007/s00268-0111010-1

9. Kikwilu EN, Frencken JE, Mulder J, Masalu JR. Barriers to restorative care as perceived by dental patients attending government hospitals in Tanzania. Community Dent. Oral Epidemiol. 2009; 37: 35-44. DOI: https://doi.org/10.1111/ j.1600-0528.2008.00446.x

10. Ozgediz D, Kijjambu S, Galukande M, Dubowitz G, Mabweijano J, Mijumbi C, Cherian M, Kaggwa S, Luboga S. Africa's neglected surgical workforce crisis. Lancet Lond. Engl. 2008; 371: 627-628. DOI: https://doi.org/10.1016/ S0140-6736(08)60279-2

11. Choo S, Perry H, Hesse AAJ, Abantanga F, Sory E, Osen H, Fleischer-Djoleto C, Moresky R, McCord CW, Cherian M, Abdullah F. Assessment of capacity for surgery, obstetrics and anaesthesia in 17 Ghanaian hospitals using a WHO assessment tool. Trop. Med. Int. Health TM IH. 2010; 15: 1109-1115. DOI: https://doi.org/10.1111/j.13653156.2010.02589.x

12. Iddriss A, Shivute N, Bickler S, Cole-Ceesay R, Jargo B, Abdullah F, Cherian M. Emergency, anaesthetic and essential surgical capacity in the Gambia. Bull. World Health Organ. 2011; 89: 565-572. DOI: https://doi.org/10.2471/ BLT.11.086892
13. Kingham TP, Kamara TB, Cherian MN, Gosselin RA, Simkins M, Meissner C, Foray-Rahall L, Daoh KS, Kabia SA, Kushner AL. Quantifying surgical capacity in Sierra Leone: a guide for improving surgical care. Arch. Surg. Chic. Ill 1960. 2009; 144: 122-127; discussion 128. DOI: https://doi. org/10.1001/archsurg.2008.540

14. Henry JA, Cotton M. Essential Surgery: The Way Forward: Reply. World J. Surg. 2015; 39: 2837-2837. DOI: https://doi. org/10.1007/s00268-015-3247-6

15. Kushner AL, Cherian MN, Noel L, Spiegel DA, Groth S, Etienne C. Addressing the Millennium Development Goals from a surgical perspective: essential surgery and anesthesia in 8 low- and middle-income countries. Arch. Surg. Chic. Ill 1960. 2010; 145: 154-159. DOI: https://doi. org/10.1001/archsurg.2009.263

16. Sader E, Yee P, Hodaie M. Assessing Barriers to Neurosurgical Care in Sub-Saharan Africa: The Role of Resources and Infrastructure, World Neurosurg. 2017; 98: 682-688.e3. DOI: https://doi.org/10.1016/j.wneu.2016.07.102

17. Malhotra AK. Global Neurosurgery What are the Current Barriers to Neurosurgical Care in Low-Middle Income Countries. Univ. Tor. Med. J. 2017; 94: 32-36.

18. Olenja J. Health seeking behaviour in context. East Afr. Med. J. 2003; 80: 61-62. DOI: https://doi.org/10.4314/eamj. v80i2.8689

19. Atuyambe L, Mirembe F, Tumwesigye NM, Annika J, Kirumira EK, Faxelid E. Adolescent and adult first time mothers' health seeking practices during pregnancy and early motherhood in Wakiso district, central Uganda. Reprod. Health. 2008; 5: 13. DOI: https://doi. org/10.1186/1742-4755-5-13

20. Mwase I. Social capital and household healthseeking behaviour for children in the context of urban neighbourhoods: The case of Khayelitsha in Western Cape. South Africa. 2015. https://open.uct.ac.za/ handle/11427/13806 (accessed March 28, 2021).

21. Onwujekwe O, Onoka C, Uzochukwu B, Hanson K. Constraints to universal coverage: inequities in health service use and expenditures for different health conditions and providers. Int. J. Equity Health. 2011; 10(50). DOI: https://doi.org/10.1186/1475-9276-10-50

22. Ogunlesi TA, Olanrewaju DM. Socio-demographic Factors and Appropriate Health Care-seeking Behavior for Childhood Illnesses. J. Trop. Pediatr. 2010; 56: 379-385. DOI: https://doi.org/10.1093/tropej/fmq009

23. Katung PY. Socio-economic factors responsible for poor utilisation of the primary health care services in a rural community in Nigeria. Niger. J. Med. J. Natl. Assoc. Resid. Dr. Niger. 2001; 10: 28-29.

24. Musoke D, Boynton P, Butler C, Musoke M. Health seeking behaviour and challenges in utilising health facilities in Wakiso district. Uganda, Afr. Health Sci. 2015; 14: 1046. DOI: https://doi.org/10.4314/ahs.v14i4.36

25. Bramall A, Djimbaye H, Tolessa C, Biluts H, Abebe M, Bernstein M. Attitudes toward neurosurgery in a low- 
income country: a qualitative study. World Neurosurg.

2014; 82: 560-566. DOI: https://doi.org/10.1016/j.

wneu.2014.05.015

26. Adeleye AO, Fatiregun AA. Breaking Bad News to a Prospective Cross-Sectional Sample of Patients' Relatives in a Nigerian Neurosurgical Service. Front. Neurol. 2013; 4. DOI: https://doi.org/10.3389/fneur.2013.00110

27. Ng'anjo Phiri S, Kiserud T, Kvåle G, Byskov J, EvjenOlsen B, Michelo C, Echoka E, Fylkesnes K. Factors associated with health facility childbirth in districts of Kenya, Tanzania and Zambia: a population based survey. BMC Pregnancy Childbirth. 2014; 14: 219. DOI: https://doi. org/10.1186/1471-2393-14-219

28. Mapuroma R. Cohen C. Kuonza L, Musekiwa A, Tempia S, Tshangela A, Von Mollendorf C. Healthcare seeking behaviour for common infectious syndromes among people in three administrative regions of Johannesburg,
South Africa, 2015: a cross-sectional study. Pan Afr. Med. J. 2019; 33. DOI: https://doi.org/10.11604/ pamj.2019.33.159.18461

29. Lahiri SN, Chatterjee A, Maiti T. Normal approximation to the hypergeometric distribution in nonstandard cases and a sub-Gaussian Berry-Esseen theorem. J. Stat. Plan. Inference. 2007; 137: 3570-3590. DOI: https://doi. org/10.1016/j.jspi.2007.03.033

30. Population of Africa (2021) - Worldometer. (n.d.). https://www.worldometers.info/world-population/africapopulation/ (accessed May 8, 2021).

31. Hirai K, Kudo T, Akiyama M, Matoba M, Shiozaki M, Yamaki T, Yamagishi A, Miyashita M, Morita T, Eguchi K. Public awareness, knowledge of availability, and readiness for cancer palliative care services: a population-based survey across four regions in Japan. J. Palliat. Med. 2011; 14: 918-922. DOI: https://doi.org/10.1089/jpm.2010.0529

\section{TO CITE THIS ARTICLE:}

Ikwuegbuenyi C, Adegboyega G, Nyalundja AD, Bamimore MA, Nteranya DS, Sebopelo LA, Kanmounye US. Public Awareness, Knowledge of Availability, And Willingness to Use Neurosurgical Care Services in Africa: A Cross-Sectional E-Survey Protocol. International Journal of Surgery: Protocols. 2021; 25(1), pp. 123-128. DOI: https://doi.org/10.29337/ijsp.149

Submitted: 08 May 2021 Accepted: 18 June 2021 Published: 13 July 2021

\section{COPYRIGHT:}

(c) 2021 The Author(s). This is an open-access article distributed under the terms of the Creative Commons Attribution 4.0 International License (CC-BY 4.0), which permits unrestricted use, distribution, and reproduction in any medium, provided the original author and source are credited. See http://creativecommons.org/licenses/by/4.0/.

International Journal of Surgery: Protocols is a peer-reviewed open access journal published by IJS Publishing Group.

\section{IJS Press}

